\title{
Evaluation of single nucleotide polymorphisms in microRNAs (hsa-miR-196a2 rs11614913 C/T) from Brazilian women with breast cancer
}

\author{
José Juvenal Linhares ${ }^{1,2^{*}}$, Marcos Azevedo $\mathrm{Jr}^{2}$, Adalberto Abraão Siufi ${ }^{2}$, Cristina Valleta de Carvalho ${ }^{2,3}$, \\ Maria Del Carmen Garcia Molina Wolgien², Emmanuelle Coelho Noronha², \\ Tatiana Carvalho de Souza Bonetti ${ }^{2,4}$ and Ismael Dale Cotrim Guerreiro da Silva ${ }^{2}$
}

\begin{abstract}
Background: Emerging evidence has shown that miRNAs are involved in human carcinogenesis as tumor suppressors or oncogenes. Single nucleotide polymorphisms (SNPs) located in pre-miRNAs may affect the processing and therefore, influence the expression of mature miRNAs. Previous studies generated conflicting results when reporting association between the hsa-miR-196a2 rs11614913 common polymorphism and breast cancer.

Methods: This study evaluated the hsa-miR-196a2 rs11614913 SNP in 388 breast cancer cases and 388 controls in Brazilian women. Polymorphism was determined by real-time PCR; control and experimental groups were compared through statistical analysis using the $X^{2}$ or Fisher's exact tests.

Results: The analysis of the SNPs frequencies showed a significant difference between the groups (BC and $C T$ ) in regards to genotype distribution $\left(X^{2}: p=0.024\right)$; the homozygous variant (CC) was more frequent in the $C T$ than in the BC group $(p=0.009)$. The presence of the hsa-miR-196a2 rs11614913 C/T polymorphism was not associated with histological grades $(p=0.522)$, axillary lymph node positive status $(p=0.805)$, or clinical stage $(p=0.670)$ among the breast cancer patients.
\end{abstract}

Conclusions: The results of this study indicated that the CC polymorphic genotype is associated with a decreased risk of $\mathrm{BC}$ and the presence of the T allele was significantly associated with an increased risk of BC.

Keywords: Breast, Cancer, Polymorphisms, MicroRNAs

\section{Background}

MiRNAs represent a recently discovered class of small regulatory RNAs that influence the stability and efficiency of target mRNAs and are implicated in a growing number of biological processes including neoplasms. Recent studies have demonstrated the involvement of these regulatory molecules in the development of breast cancer $(\mathrm{BC})[1]$.

\footnotetext{
* Correspondence: juvenalinhares@gmail.com

'Department of Gynecology and Obstetrics, Federal University of Ceará (Campus Sobral), Av. Humberto Lopes, 200, Junco, Sobral, Ceará CEP: 62022-304, Brazil

${ }^{2}$ Molecular Gynecology Laboratory, Department of Gynecology, Federal University of São Paulo, Rua Pedro de Toledo, 781 - 4o. Floor, Vila Clementino, São Paulo-SP CEP: 04039-032, Brazil

Full list of author information is available at the end of the article
}

Zhang et al. compared the expression patterns of miRNAs between healthy and BC mammary tissues and observed, preliminarily, that various miRNAs are expressed in different ways in BC. This observation lead to the hypothesis that expression profiles of miRNAs could be correlated with special tumor phenotypes or associated with tumor suppression or tumorigenesis [2]. Iorio et al., using microarray analysis, demonstrated that aberrant expression of miRNAs is associated with human BC [3].

MiRNAs have an enormous potential as biomarkers of $\mathrm{BC}$ because their expression is known to be aberrant in cancer with pathognomonic profiles, that is, related to specific tissues; in addition, they are notably stable molecules that remain well preserved in formalin, paraffinembedded tissues, and fresh or frozen tissues $[4,5]$.

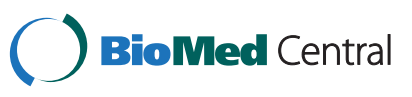


A strong association between miRNA polymorphisms and risk of cancer has been established and, thus provides supporting pathways for the investigation of molecular mechanisms involved in the development of cancer. The loss or gain of function of particular miRNAs are also involved in events during the genesis of various types of cancer, including $\mathrm{BC}$ [6]. For example, hsa-mir-10B has been identified as an initiator of invasion and metastasis in $\mathrm{BC}$ [7], where expression patterns are altered in human $\mathrm{BC}[3,8]$.

Because $\mathrm{BC}$ is an estrogen-dependent tumor, mechanisms involving the estrogen receptor have been considered in studies addressing the molecular understanding of this disease. Estrogen receptors have been recently shown to be regulated by miRNAs as well as other cofactors. miRNAs are regulatory RNA molecules that have been foremost in the molecular investigation of many diseases and cellular processes. They exert their effect directly on target genes resulting in transcriptional repression or degradation of the target sequence $[9,10]$.

The hsa-miR-196a2 rs11614913 polymorphism, located on chromosome 12 (12q13.13), appears to regulate the Hox gene in a subgroup of the homeobox genes. This subgroup controls the development and positional differentiation of cells in the embryo. Thus, the prediction of the miRNAs that would target homeobox genes (together with genes that have an important function in development through the control of the parts of the embryo that will develop into organs and specific tissues) seem to be an especially attractive area for the investigation of breast cancer development [11].

The modulation of the p53 gene expression is controled by HOX proteins that bind to its promoter region $[12,13]$. In addition, the expression of these proteins can lead to inhibition of p53-dependent apoptosis in $\mathrm{BC}$ cells. Therefore, the decreased gene expression in mammary tumors can act on p53, firstly through the promotion of genome instability, and secondly through opposing mechanisms that lead to apoptosis there after $[10,12,14]$.

In a case-control study with Chinese women with breast cancer, the genotype variant of hsa-miR-196a2 rs11614913 was associated with a significantly increased risk of $\mathrm{BC}$ [15].That study provided the first evidence that SNPs, common in miRNAs, could be utilized as candidate biomarkers for BC susceptibility.

A recent case-control study with Italian and German women that evaluated miRNAs polymorphisms showed that the hsa-miR-196a2 rs11614913 genotype was not associated with increased risk of BC [16].

The correlations between the hsa-miR-196a2 rs11614913 $\mathrm{C} / \mathrm{T}$ SNP and development of breast cancer are controversially reported in the literature. Moreover, there are no relevant studies in South American populations reporting on this subject. Hence, this study assessed the presence of hsa-miR-196a2 rs11614913 polymorphisms in microRNA sequences from Brazilian women with and without breast cancer and its association with breast cancer.

\section{Methods}

\section{Subjects}

The Research Ethics Committee from the Federal University of Sao Paulo (No. 0211/08) approved this study; signed informed consents were obtained from all participants before the study start. The study included 388 women diagnosed between April 2004 and July 2010 with invasive ductal breast carcinoma ( $\mathrm{BC}$ group) in the Mastology Division of the "Francisco Morato Oliveira" Hospital (HSPE-FMO) and Federal University of São Paulo (UNIFESP-EPM) in Brazil. The diagnosis of breast carcinoma was reached through clinical and radiological examinations (mammography and/or ultrasonography) and subsequently confirmed by the histopathological assessment of biopsies. Peripheral blood samples were collected regardless of the clinical stage or previous treatment. Pregnant women or patients under hormonal therapy (HT) were excluded from the study.

The control group (CT group) included samples of oral mucosal scrapings obtained from 388 women without breast cancer attending the Menopause and Gynecology Clinic for routine consultations at the same institutions mentioned above. These patients were also screened for breast cancer through clinical and radiological examinations (mammography and/or ultrasound); patients under hormonal therapy (HT), pregnant, or with a prior history of breast biopsy were excluded. The oral samples from these patients were collected using a Cytobrush $^{\circledR}$ and stored in dry tubes.

Data from all patients were collected in a standardized form containing information about age, race (Caucasianornon-Caucasian), age at menarche (under or over 12 years of age), pre or post-menopausal status, family history of breast cancer (first-degree relative: mother, sister, or daughter), the habit of smoking, cancer clinical stage, axillary lymph node status, and Scarff-Bloom-Richardson (SBR) histological grade.

\section{Genotyping}

DNA was extracted from blood and oral mucosal scrapping samples according to the protocol for the GFX ${ }^{\circledR}$ kit for cells, tissues, and blood (Amersham-Pharmacia).

The hsa-miR-196a2 rs11614913 C/T SNP was genotyped using the Custom TaqMan ${ }^{\circledR}$ SNP Genotyping Assays (Applied Biosystems, ID C_31185852_10). Between 1 and $20 \mathrm{ng}$ of DNA was used per PCR reaction performed in duplicates at the final volume of $20 \mathrm{ul}$ 
using the ABI 7500 Real-Time PCR detection System (Applied Biosystems ${ }^{\circledR}$ ).

The cycling conditions were $50^{\circ} \mathrm{C}$ for $2 \mathrm{~min}, 95^{\circ} \mathrm{C}$ for $10 \mathrm{~min}, 40$ cycles of at $92^{\circ} \mathrm{C}$ for $15 \mathrm{~s}$, and annealing/ extension at $60^{\circ} \mathrm{C}$ for $1 \mathrm{~min}$. The data were analyzed using the SDS Software v. 1.3.1.

\section{Statistical analysis}

The outcomes were analyzed taking into consideration the patients' characteristics assessed in the standardized form used for data collection. First-degree relatives such as mother, sisters, or daughters were considered in the assessment of family history of breast cancer.

The demographic characteristics of the groups were compared by the Student's t-test for continuous variables and the qui-squared test $\left(\chi^{2}\right)$ for nominal variables. The Pearson's chi-square test was used to assess the correlation between variables; multiple linear and logistic regression models were used to evaluate associations between genotypes, alleles, and occurrence of breast cancer. The CC genotype was considered as the reference for comparisons with the TC (heterozygote) and TT (homozygote) variants. The sample power was calculated based on the proportion of patients with at least one mutated allele (TC or TT). The sample power in this study was 0.77 considering an alpha error $=0.05$. The SPSS 15 statistical software was used for data analyses and a $\mathrm{p}$ value $\leq 0.05$ was considered statistically significant.

\section{Results}

The demographic characteristics and risk factors associated with the $\mathrm{BC}$ and $\mathrm{CT}$ groups are shown in Table 1. The $\mathrm{BC}$ group presented an average age that was 2.6 years older than the CT group and a higher percentage of non-Caucasian patients. Axillary lymph node positive status was observed in $45.8 \%$ of the patients in the $\mathrm{BC}$ group; breast cancer histological grades and clinical stages are shown in Table 1.

The genotype distribution in the $\mathrm{CT}$ and $\mathrm{BC}$ groups are shown in Table 2; 100\% concordance was observed between the results from the samples' duplicates. The analysis of the frequencies showed a significant difference in genotype distribution between groups (BC and CT) $\left(x^{2}: p=0.024\right)$; the homozygous variant $(C C)$ was more frequent in the $\mathrm{CT}$ group than in the $\mathrm{BC}$ group $(\mathrm{p}=0.009)$.

The Brazilian population is characterized by a mixture of races, which justifies the HWE deviation in the distribution of genetic variants. Thus, the HWE was calculated based on Caucasian or non-Caucasian races in both groups, the control group $(\mathrm{p}=0.008$ and 0.264$)$, and $\mathrm{BC}$ group $(\mathrm{p}=0.112$ and $\mathrm{p}=0.723)$. The control
Table 1 Summary of demographic characteristics and risk factors for breast cancer development

\begin{tabular}{|c|c|c|c|}
\hline VARIABLE & $\begin{array}{l}\text { CT group } \\
(\mathrm{n}=388)\end{array}$ & $\begin{array}{l}B C \text { group } \\
(\mathrm{n}=388)\end{array}$ & $p$ value \\
\hline Age in years (mean $\pm S D$ ) & $55.1 \pm 10.3$ & $57.7 \pm 12.6$ & 0.008 \\
\hline $\begin{array}{l}\text { Age at menarche in years } \\
\text { (mean } \pm \text { SD) }\end{array}$ & $12.9 \pm 1.6$ & $13.0 \pm 1.6$ & 0.700 \\
\hline \multicolumn{4}{|l|}{ Race } \\
\hline Caucasian & $19.4 \%$ & $16.2 \%$ & $<0.001$ \\
\hline Non-Caucasian & $70.6 \%$ & $83.8 \%$ & \\
\hline Patients at Menopause & $66.8 \%$ & $63.9 \%$ & 0.225 \\
\hline Habit of smoking & $26.3 \%$ & $22.4 \%$ & 0.240 \\
\hline $\begin{array}{l}\text { First-degree family history } \\
\text { of breast cancer }\end{array}$ & $16.7 \%$ & $18.0 \%$ & 0.635 \\
\hline \multicolumn{4}{|l|}{ Histological Grade } \\
\hline 1 & -— & $24.5 \%$ & -— \\
\hline 2 & -— & $47.9 \%$ & -— \\
\hline 3 & - & $27.6 \%$ & - \\
\hline \multicolumn{4}{|l|}{ Clinical stages } \\
\hline 1 & -— & $34.5 \%$ & -— \\
\hline 2 & - & $43.8 \%$ & -- \\
\hline 3 & - & $16.0 \%$ & - \\
\hline 4 & - - & $5.7 \%$ & - - \\
\hline
\end{tabular}

Caucasian group presented an unbalanced distribution of variants (Table 3 ).

A multiple logistic regression analysis was conducted to evaluate the association of the hsa-miR-196a2 rs11614913 C/T polymorphism adjusted for interfering variables as age, race, menarche age, menopausal status, smoking habits, and first-degree breast cancer family history. The presence of the TC or TT variants increased the risk of breast cancer in 50\% when adjusted for the confounding variables (Table 4).

The presence of the hsa-miR-196a $2 \mathrm{rs} 11614913 \mathrm{C} / \mathrm{T}$ polymorphism was not associated with histological grade $(\mathrm{p}=0.522)$, axillary lymph node positive status $(\mathrm{p}=0.805)$, or clinical stage $(\mathrm{p}=0.670)$ among breast cancer patients. On the other hand, histological grade was negatively associated with age (Pearson correlation: $\mathrm{r}=-0.106 ; \mathrm{p}=0.037)$ and positively associated with smoking (Pearson correlation: $r=0.106 ; p=0.038$ ). The

Table 2 Genotype distribution in the CT and BC groups

\begin{tabular}{llcccc}
\hline GROUPS & & \multicolumn{3}{c}{ Genotype } & HWE \\
\cline { 3 - 5 } & & CC & TC & TT & \\
\hline CT & Count & 127 & 165 & 96 & 0.004 \\
\cline { 2 - 5 } & \% within Group & $32.7 \%$ & $42.5 \%$ & $24.7 \%$ & \\
\hline BC & Count & 94 & 177 & 117 & 0.096 \\
\hline & \% within Group & $24.2 \%$ & $45.6 \%$ & $30.2 \%$ & \\
\hline
\end{tabular}

HWE: Hardy-Weinberg Equilibrium. $x^{2}: p=0.024$. 
Table 3 Genotype distribution in the CT and BC groups based on races

\begin{tabular}{lllclll}
\hline GROUPS & & \multicolumn{3}{c}{ Genotype } & HWE \\
\cline { 2 - 5 } & & CC & TC & TT & \\
\hline CT Caucasian & Count & 94 & 114 & 66 & 0.008 \\
\cline { 2 - 6 } & \% within Group & $34.3 \%$ & $41.6 \%$ & $24.1 \%$ & \\
\hline CT non-Caucasian & Count & 33 & 51 & 30 & 0.264 \\
\cline { 2 - 5 } & \% within Group & $29.0 \%$ & $44.7 \%$ & $26.3 \%$ & \\
\hline BC Caucasian & Count & 83 & 148 & 94 & 0.112 \\
\cline { 2 - 5 } & \% within Group & $25.5 \%$ & $45.6 \%$ & $28.9 \%$ & \\
\hline BC non-Caucasian & Count & 11 & 29 & 23 & 0.723 \\
\cline { 2 - 5 } & \% within Group & $17.5 \%$ & $46.0 \%$ & $36.5 \%$ & \\
\hline
\end{tabular}

HWE: Hardy-Weinberg Equilibrium.

axillary lymph node positive status was positively associated with a family history of breast cancer (Pearson correlation: $\mathrm{r}=0.190 ; \mathrm{p}<0.001)$. The clinical stage of breast cancer was not associated with the hsa-miR-196a2 rs11614913 C/T polymorphism or demographic variables.

\section{Discussion}

The growing interest in evaluating the association between the hsa-miR-196a2 rs11614913 SNP and development of BC [3,4,15-17], along with the lack of studies in Latin America on this subject, were the foundations for this study.

Many associations between miRNAs and occurrence of $\mathrm{BC}$ have been demonstrated experimentally. The understanding of the mechanisms involved in these associations could establish the use of these markers (miRNAs) as powerful tools for the prevention and treatment of BC [9].

MiRNAs are involved in critical biological processes including development, differentiation, apoptosis, and proliferation. Genetic polymorphisms of miRNAs (SNPs) can potentially influence the processing or selection of miRNA targets. The association between hsa-miR-196a2 rs11614913 SNPs and susceptibility to develop breast

Table 4 Multiple logistic regression analysis adjusted for the interfering variables to evaluate the association between polymorphism and occurrence of BC

\begin{tabular}{lcccc}
\hline & Constant & SE & OR & $\boldsymbol{P}$ \\
\hline Presence of TC or TT variant & 0.406 & 0.165 & 1.501 & 0.014 \\
\hline Age (years) & 0.023 & 0.008 & 1.024 & 0.003 \\
\hline Non-Caucasian race & -0.786 & 0.180 & 0.456 & 0.000 \\
\hline Age at Menarche (years) & 0.021 & 0.047 & 1.021 & 0.660 \\
\hline Menopause (yes or no) & -0.523 & 0.194 & 0.593 & 0.007 \\
\hline Smoking (yes or no) & -0.192 & 0.190 & 0.825 & 0.311 \\
\hline BC Family history (yes or no) & -0.291 & 0.187 & 0.748 & 0.119 \\
\hline Constant & -1.244 & 0.733 & 0.288 & 0.090 \\
\hline SE: stand
\end{tabular}

SE: standard error. OR: odds ratio. cancer have been evaluated by several recent studies $[15,16,18]$.

Considering the important role of hsa-miR-196a2 rs11614913 in the carcinogenic process of breast cancer, the present study evaluated the distribution of this genotype and estimated the risk of the development of $\mathrm{BC}$ in Brazilian women.

Predominance of the TC genotype (heterozygote) was observed in the subjects in the study and corroborated the data reported in the literature $[15,16,18]$. The analyzed groups in this study were representative of a miscegenated population (Brazilians) and cannot be compared with other studied populations. The predominant allele distribution observed in this population did not diverge from that reported in the literature, despite the miscegenation, suggesting that the heterozygous form is the most prevalent worldwide.

$\mathrm{Hu}$ et al. observed an increased risk of breast cancer associated to the TC/CC genotypes with OR of 1.23 (1.02-1.48) when studying an Asian population [15]. Gao et al. conducted a meta-analysis of the hsa-miR$196 \mathrm{a} 2$ distribution that suggested that women with the CC polymorphic genotype had an increased risk of breast cancer with OR of 1.30 (1.01-1.68) [19]. Nevertheless, the results from these studies remain conflicting and inconclusive [19]. Conversely, Catucci et al. did not identify statistical correlations between the presence of hsa-miR-196a2 rs11614913 in women with breast cancer and controls in German and Italian populations [16]. The present study produced different results showing an association between the presence of the $\mathrm{T}$ ( TC/ TT) allele and increased risk of $\mathrm{BC}$ with $\mathrm{OR}$ of 1.52 (1.11-2.08); in addition, the results indicate that the CC (mutant homozygous) polymorphic genotype acted as a protective factor with OR of 0.61 (0.42-0.89). The discordant results could be suggestive of the extensive miscegenation between different ethnic groups in the Brazilian population, which could lead to increased genetic variability. In a meta-analysis including different populations, where a statistical rearrangement was performed, the tendency of the hsa-miR-196a2 rs11614913 SNP to act as a protective factor against breast cancer was observed with OR of $0.83(0.77-1.03)$ and $p=0.07$; these results corroborate the results observed in the meta-analysis [16]. Wang et al. observed that the increased risk of $\mathrm{BC}$ associated with the $\mathrm{CC}$ genotype was present in Chinese and Indian women but not in Caucasian women; the latter being closer to the Brazilian population than the Asian populations [20].

\section{Conclusions}

The results obtained in this study relative to the hsamiR-196a2 rs11614913 SNP in the Brazilian population indicated that the $\mathrm{CC}$ polymorphic genotype is 
associated with a decreased risk of $\mathrm{BC}$, and the presence of the $\mathrm{T}$ allele is significantly associated with an increased risk of BC. Further studies with larger sample sizes and in populations with similar ethnic background could contribute in supporting the results presented in the current study.

\section{Abbreviations}

BC: Breast cancer; OR: Odds ratio; Cl: Confidence interval; HSPE-FMO: "Francisco morato oliveira" hospital; UNIFESP-EPM: Federal university of são paulo, brazil; SBR: Scarff-bloom-richardson.

\section{Competing interests}

The authors declare that they have no competing interests.

\section{Authors' contributions}

$J J L$ participated in the design of the study, statistical analysis, and manuscript preparation. MAJ and ECN analyzed the data from the real time PCR assays. AAS, CVC, and MDCGMW participated in sample collection. TCSB performed the statistical analyses. IDCGS participated in the design of the study and manuscript preparation. All authors read and approved the final manuscript.

\section{Acknowledgements}

The authors are thankful to all members of the Molecular Gynecology Laboratory.

\section{Author details}

'Department of Gynecology and Obstetrics, Federal University of Ceará (Campus Sobral), Av. Humberto Lopes, 200, Junco, Sobral, Ceará CEP: 62022-304, Brazil. ${ }^{2}$ Molecular Gynecology Laboratory, Department of Gynecology, Federal University of São Paulo, Rua Pedro de Toledo, 781 - 40. Floor, Vila Clementino, São Paulo-SP CEP: 04039-032, Brazil. ${ }^{3}$ Biology Department, Centro Universitário Fundação Santo André, São Paulo-SP, Brazil. ${ }^{4}$ Reproductive Biology Research Laboratory, Division of Reproductive Endocrinology and Infertility, Department of Obstetrics and Gynecology, University of South Florida - USF, MDC 2147, 12901 Bruce B Downs Blvd, Tampa, FL 33612, USA.

Received: 7 August 2012 Accepted: 30 November 2012 Published: 10 December 2012

\section{References}

1. Verghese ET, Hanby AM, Speirs V, Hughes TA: Small is beautiful: microRNAs and breast cancer - where are we now? J Pathol 2008, 215:214-221.

2. Zhang L, Yang N, Coukos G: MicroRNA in human cancer: one step forward in diagnosis and treatment. Adv Exp Med Biol 2008, 622:69-78.

3. Lorio MV, Ferracin M, Liu CG, Veronese A, Spizzo R, Sabbioni S, Magri E, Pedriali M, Fabbri M, Campiglio M, Ménard S, Palazzo JP, Rosenberg A, Musiani P, Volinia S, Nenci I, Calin GA, Querzoli P, Negrini M, Croce CM: MicroRNA gene expression deregulation in human breast cancer. Cancer Res 2005, 65:7065-7070.

4. Heneghan HM, Miller N, Lowery AJ, Sweeney KJ, Kerin MJ: MicroRNAs as novel biomarkers for breast cancer. J Oncol 2009, 2010:1-7.

5. Heneghan HM, Miller M, Kerin MJ: Circulating microRNAs: promising breast cancer biomarkers. Breast Cancer Res 2011, 13:402.

6. Esquela-Kerscher A, Slack FJ: Oncomirs-microRNAs with a role in cancer. Nat Rev Cancer 2006, 6:259-269.

7. Ma L, Teruya-Feldstein J, Weinberg RA: Tumor invasion and metastasis initiated by microRNA-10b in breast cancer. Nature 2007, 449:682-688

8. Sempere LF, Christensen M, Silahtaroglu A, Bak M, Heath CV, Schwartz G, Wells W, Kauppinen S, Cole CN: Altered microRNA expression confined to specific epithelial cell subpopulations in breast cancer. Cancer Res 2007, 67:11612-11620

9. McCafferty MPJ, McNeill RE, Miller N, Kerin MJ: Interactions between the estrogen receptor, its cofactors and microRNAs in breast cancer. Breast Cancer Res Treat 2009, 116:425-432.

10. Lee YM, Lee JY, Ho CC, Hong QS, Yu SL, Tzeng CR, Yang PC, Chen HW: MicroRNA 34b as a tumor suppressor in estrogen-dependent growth of breast cancer cells. Breast Cancer Res 2011, 13:116.
11. Xu J, Hu Z, Xu ZF, Gu H, Yi L, Cao H, Chen J, Tian T, Liang J, Lin Y, Qiu W, $\mathrm{Ma} H$, Shen $\mathrm{H}$, Chen Y: Functional variant in microRNA-196a2 contributes to the susceptibility of congenital heart disease in a Chinese population. Hum Mutat 2009, 30(8):1231-1236.

12. Boucherat O, Guillou F, Aubin J, Jeannotte L: Hoxa5: a master gene with multifaceted roles. Med Sci (Paris) 2009, 25(1):77-82

13. Raman V, Martensen SA, Reisman D, Evron E, Odenwald WF, Jaffee E, Marks J, Sukumar S: Compromised HOXA5 function can limit p53 expression in human breast tumors. Nature 2000, 405:974-978.

14. Xu W, Xu J, Liu S, Chen B, Wang X, Li Y, Qian Y, Zhao W, Wu J: Effects of common polymorphism rs11614913 in miR-196a2 and rs2910164 on cancer susceptibility: a meta-analysis. PLoS One 2011, 6(5):e20471.

15. Hu Z, Liang J, Tian T, Zhou X, Chen J, Miao R, Wang Y, Wang X, Shen H: Common genetic variants in Pre-MicroRNAs were associated with increased risk of breast cancer in Chinese women. Hum Mutat 2009, 30(1):79-84

16. Catucci I, Yang R, Verderio P, Pizzamiglio S, Heesen L, Hemminki K, Sutter C, Wappenschmidt B, Dick M, Arnold N, Bugert P, Niederacher D, Meindl A, Schmutzler RK, Bartram CC, Ficarazzi F, Tizzoni L, Zaffaroni D, Manoukian S, Barile M, Pierotti MA, Radice P, Burwinkel B, Peterlongo P: Evaluation of SNPs in miR-146a, miR196a2 and miR-499 as low-penetrance alleles in German and Italian familial breast cancer cases. Hum Mutat 2010, 31 (1):1052-1057.

17. Catucci I, Verderio P, Pizzamiglio S, Manoukian S, Peissel B, Zaffaroni D, Roversi G, Ripamonti CB, Pasini B, Barile M, Viel A, Giannini G, Papi L, Varesco L, Martayan A, Riboni M, Volorio S, Radice P, Peterlongo P: The CASP8 rs3834129 polymorphism and breast cancer risk in BRCA1 mutation carriers. Breast Cancer Res Treat 2011, 125(3):855-860

18. Hoffman AE, Zheng T, Yi C, Leaderer D, Weidhaas J, Slack F, Zhang Y, Paranjape T, Zhu Y: MicroRNA miR-196a-2 and breast cancer: a genetic and epigenetic association study and functional analysis. Cancer Res 2009, 69:5970-5977.

19. Gao LB, Bai P, Pan XM, Jia J, Li LJ, Liang WB, Tang M, Zhang LS, Wei YG, Zhang $L$ : The association between two polymorphisms in pre-miRNAs and breast cancer risk: a meta-analysis. Breast Cancer Res Treat 2011, 125(2):571-574.

20. Wang F, Ma YL, Zhang P, Yang JJ, Chen HQ, Liu ZH, Peng JY, Zhou YK, Qin HL: A genetic variant in microRNA-196a2 is associated with increased cancer risk: a meta-analysis. Mol Biol Rep 2012, 39(1):269-275.

doi:10.1186/1471-2350-13-119

Cite this article as: Linhares et al:: Evaluation of single nucleotide polymorphisms in microRNAs (hsa-miR-196a2 rs11614913 C/T) from Brazilian women with breast cancer. BMC Medical Genetics 2012 13:119.

\section{Submit your next manuscript to BioMed Central and take full advantage of:}

- Convenient online submission

- Thorough peer review

- No space constraints or color figure charges

- Immediate publication on acceptance

- Inclusion in PubMed, CAS, Scopus and Google Scholar

- Research which is freely available for redistribution 